\title{
A mediation analysis of the role of girl child marriage in the relationship between proximity to conflict and past-year intimate partner violence in post-conflict Sri Lanka
}

Ruvani W. Fonseka ${ }^{1,2,3^{*}}$ D, Lotus McDougal' , Anita Raj ${ }^{1}$, Elizabeth Reed ${ }^{4}$, Rebecka Lundgren ${ }^{1}$, Lianne Urada ${ }^{1,5}$ and Jay G. Silverman ${ }^{1}$

\begin{abstract}
Background: Studies from many contexts indicate that proximity to conflict is associated with increased likelihood of intimate partner violence (IPV), and girl child marriage is associated with both proximity to conflict and increased IPV. In this study, we consider whether girl child marriage acts as a mediator of the association between proximity to conflict and IPV in the context of Sri Lanka, which sustained long-term conflict until 2009.

Methods: We analyzed responses of currently partnered women between ages 18 and 49 in the 2016 Sri Lankan Demographic and Health Survey $(N=13,691)$. Using logistic regression analyses, we measured associations between proximity to conflict (residence in districts which were central, proximal, or distal to the regions where the war occurred) and the outcomes of IPV and girl child marriage, and secondarily assessed girl child marriage as a possible mediator of the association between proximity to conflict and past year IPV.

Results: Women residing in districts central to conflict, as compared to districts distal to conflict, had increased odds of past year sexual, physical, and emotional IPV, with the odds of sexual IPV increasing the most (adjusted odds ratio/ aOR 4.19, 95\% confidence interval/Cl 2.08-8.41). Residing in districts proximal to conflict compared to those distal to conflict was associated with lower odds of past year physical and emotional IPV, with the greatest decrease in emotional IPV (aOR 0.31, Cl 0.18-0.54). Girl child marriage was more likely in districts central to conflict as opposed to those distal to conflict (aOR 1.89, Cl 1.22-2.93), and partially mediated the relationship between centrality to conflict and IPV.

Conclusions: Our findings demonstrate that residing in districts central to conflict compared to those distal to conflict is associated with greater odds of IPV and girl child marriage in post-conflict Sri Lanka, with girl child marriage partially mediating the association between centrality to conflict and IPV. Residence in districts proximal to conflict appears protective against IPV. Future research should investigate what factors are responsible for decreased IPV in districts proximal to violence, and whether these factors can be reproduced to mitigate the increased prevalence of IPV in districts central to conflict.
\end{abstract}

*Correspondence: rfonseka@post.harvard.edu

${ }^{1}$ Center on Gender Equity and Health (GEH), University of California San Diego School of Medicine, La Jolla, CA, USA

Full list of author information is available at the end of the article permits use, sharing, adaptation, distribution and reproduction in any medium or format, as long as you give appropriate credit to the original author(s) and the source, provide a link to the Creative Commons licence, and indicate if changes were made. The images or other third party material in this article are included in the article's Creative Commons licence, unless indicated otherwise in a credit line to the material. If material is not included in the article's Creative Commons licence and your intended use is not permitted by statutory regulation or exceeds the permitted use, you will need to obtain permission directly from the copyright holder. To view a copy of this licence, visit http://creativecommons.org/licenses/by/4.0/. The Creative Commons Public Domain Dedication waiver (http://creativeco mmons.org/publicdomain/zero/1.0/) applies to the data made available in this article, unless otherwise stated in a credit line to the data. 
Keywords: Sri Lanka, Intimate partner violence, Post-conflict setting, Girl child marriage, South Asia, Gender-based violence, Mediation analysis, Demographic and Health Survey (DHS)

\section{Background}

Intimate partner violence (IPV) is a pressing public health issue across the world [1]. Across South Asia, the prevalence of IPV is estimated to be $41 \%$ [2]. Within the South Asian region, the risk factors and prevalence of IPV have not been studied to the same extent in Sri Lanka as in other countries due to the recent 30-year civil war, which ended in 2009 [3]. Multiple province- and district-level surveys have estimated the prevalence of IPV in post-conflict Sri Lanka to range from 30 to $40 \%$, similar to the regional average. [4-6].

One potential driver of IPV in post-conflict Sri Lanka that is distinct from many other South Asian countries is proximity to areas where recent armed conflict occurred. In post-conflict settings in Sub-Saharan Africa, residing in conflict-affected areas has been shown to be associated with increased risk of IPV [7] and to impact mental health. $[8,9]$ Some of the identified risk factors of increased IPV in these settings include alcohol use [10, $11]$, war-related traumas [12,13], changing gender norms and roles [14], and economic stressors including poverty and unemployment $[10,14]$. Over the course of Sri Lanka's 30-year civil war, portions of the Northern and Eastern provinces were claimed as a separate state by the Liberation Tigers of Tamil Eelam (LTTE) organization [3]. Residents of the Northern and Eastern provinces were exposed to tremendous amounts of military violence and collective trauma, by both separatist and government forces [15]. The 2016 Sri Lankan Demographic and Health Survey (DHS), administered seven years after the end of the war, highlighted past year IPV prevalence rates of over $50 \%$ in multiple districts central to the conflict areas, providing evidence of a possible association between conflict exposure and IPV [16]. This possible association has been further supported by unpublished analyses of DHS data which considered conflict exposure as a binary variable. [17].

Girl child marriage has been shown in multiple settings to be associated with increased likelihood of IPV over a woman's lifetime $[18,19]$, and to increase in communities that have experienced armed conflict [20-23]. The region of South Asia has the second-highest prevalence of girl child marriage in in the world (29\%) [24], and girl child marriage has been found to be associated with increased likelihood of IPV in both India and Bangladesh $[25,26]$. In Sri Lanka, the singulate mean age of marriage (SMAM, a standard measure used to compare age of marriage across populations [27]) for women has risen and dipped over time, rather than the steady increase seen in neighboring countries and among Sri Lankan men, suggesting that the age of marriage for Sri Lankan women and girls is responsive to cultural shocks [28]. The legal minimum age of marriage in Sri Lanka for almost all women and girls is 18 [29]. During the war, girl child marriage was reported to be widely practiced among communities in areas central to the conflict, with nearly one in three women (31\%) in one study reporting having been married by age 18 [30], compared to a national prevalence in the 2016 DHS of fewer than one in nine women (11.6\%) [16]. Qualitative research conducted during and after the war's end found that early marriage was considered to be a protective strategy used by families to prevent their children from being recruited as combatants or experiencing sexual violence related to the conflict and displacement [30,31]. Although these early marriage practices were reported to have started during the war, they have continued in war-affected communities in post-conflict Sri Lanka [31]. New norms, such as increased practice of underage customary marriages, have led to younger girls being married extralegally [31]. Research documenting that girl child marriage is associated with later IPV [19], combined with evidence that girl child marriage increased in Sri Lanka as a result of the conflict, suggests that girl child marriage could serve as a mediating factor between exposure to conflict and the experience of recent IPV.

This study aimed to understand the relationship between proximity to conflict and recent IPV experience in post-conflict Sri Lanka, and to test whether girl child marriage mediates this relationship. Analyzing the 2016 Demographic and Health Survey (DHS) data from Sri Lanka, we tested four hypotheses: (1) women in districts central to conflict will have increased odds of past year sexual, physical, and emotional IPV compared to women in districts distal to conflict; (2) women in districts central to conflict will have increased odds of having married as a child compared to women in districts distal to conflict; (3) women who married as children will have increased odds of past year sexual, physical, and emotional IPV compared to women married as adults; and (4) having married as a child will mediate the associations between proximity to conflict and past year IPV experience. The results of this study will build understanding of the relationships between conflict, girl child marriage, and IPV in Sri Lanka. Such knowledge may inform 
policymakers' efforts to develop post-conflict interventions to prevent future violence.

\section{Methods}

\section{Data source}

This study used data from the 2016 Sri Lankan Demographic and Health Survey (DHS), which collected individual-level data on child and maternal health outcomes, domestic violence experience, reproductive health, and economic engagement and agency of women in Sri Lanka $(\mathrm{N}=27,210$ households, 18,510 women aged 15-49). The 2016 survey was the first DHS to be conducted among a nationally-representative sample of households in Sri Lanka-all previous DHS data collection occurred during the 30-year civil war and excluded portions of the Northern and Eastern provinces.

In addition to a general health survey administered to every eligible woman in each household, a domestic violence module was administered to one randomly selected woman in each household $(n=16,629)$. The 2016 DHS was the first to ask questions on experience of past year intimate partner violence (IPV) in Sri Lanka. Multiple peer-reviewed studies have investigated child health [32, 33], postnatal care [34], and household decision-making [35] using data from the 2016 DHS. However, to date, no peer-reviewed studies have been published using the IPV data gathered in the domestic violence module. Following the World Health Organization's guidelines for the ethical collection of information on domestic violence, each module respondent was read an additional consent statement at the start of the module, informing her that the questions could be personal and reassuring her of the confidentiality of her responses, and the module was not implemented if privacy could not be obtained [36]. In the 2016 DHS, women taking part in the domestic violence module were asked nine questions about their experiences of intimate partner violence in the previous 12 months. [16] This study was restricted to women who were currently living with an intimate partner and who answered the domestic violence module of the DHS. This study was also restricted to women age 18 and above, following a convention in girl child marriage research to exclude girls still within the window of risk for girl child marriage [37]. This practice is followed because it is possible that unmarried girls might marry after survey data collection but before their $18^{\text {th }}$ birthday. The complete sample of women included in this study comprised of 13,691 participants. Ethical approval for this secondary analysis of de-identified data was obtained from the University of California, San Diego Institutional Review Board (Project number \#191418XX).

\section{Variables of interest \\ Dependent variables: past year intimate partner violence (IPV) - sexual, physical, or emotional}

We examined three different IPV variables as dependent variables of interest. The three binary variables are listed below:

1. Past year sexual IPV: having been forced to have sex by a partner in the last 12 months; yes or no.

2. Past year physical IPV: having experienced at least one of six types of physical IPV in the last 12 months: (1) slapping or beating with a hand, (2) pushing or shoving, (3) strangulation, (4) dragging or pulling, (5) beating with an object, or (6) burned; yes, or no.

3. Past year emotional IPV: having experienced at least one of two types of emotional IPV in the last 12 months: (1) being belittled/offended or (2) prevented from leaving home by a partner; yes or no.

In our analyses, we considered sexual, physical, and emotional IPV as separate outcomes, based on Spearman's rho correlation estimates across all three IPV variables remaining below 0.5 .

\section{Independent variable: proximity to conflict}

We included proximity to conflict as the independent variable in our analyses. This variable was defined as having three ordinal levels: distal, proximal and central. Participants assigned to the distal category resided in districts that were neither in nor bordering the Northern and Eastern provinces of the country, where most of the armed conflict occurred during the civil war. Distal districts included Colombo, Galle, Gampaha, Kalutara, Kandy, Kegalle, Kurunegala, Matara, Nuwara Eliya, and Ratnapura. Participants assigned to the proximal category reported residing in one of the seven districts of Sri Lanka outside of but sharing a border with at least one district within the Northern and Eastern provinces. Proximal districts included Anuradhapura, Badulla, Hambantota, Matale, Monaragala, Polonnaruwa, and Puttalam. Finally, participants assigned to the central category reported residing in a district located within either the Northern or Eastern provinces of Sri Lanka. Central districts included Ampara, Batticaloa, Jaffna, Kilinochchi, Mannar, Mullaitivu, Trincomalee, and Vavuniya. A map of Sri Lanka showing the geographic distribution of proximity to conflict is included as Fig. 1. 


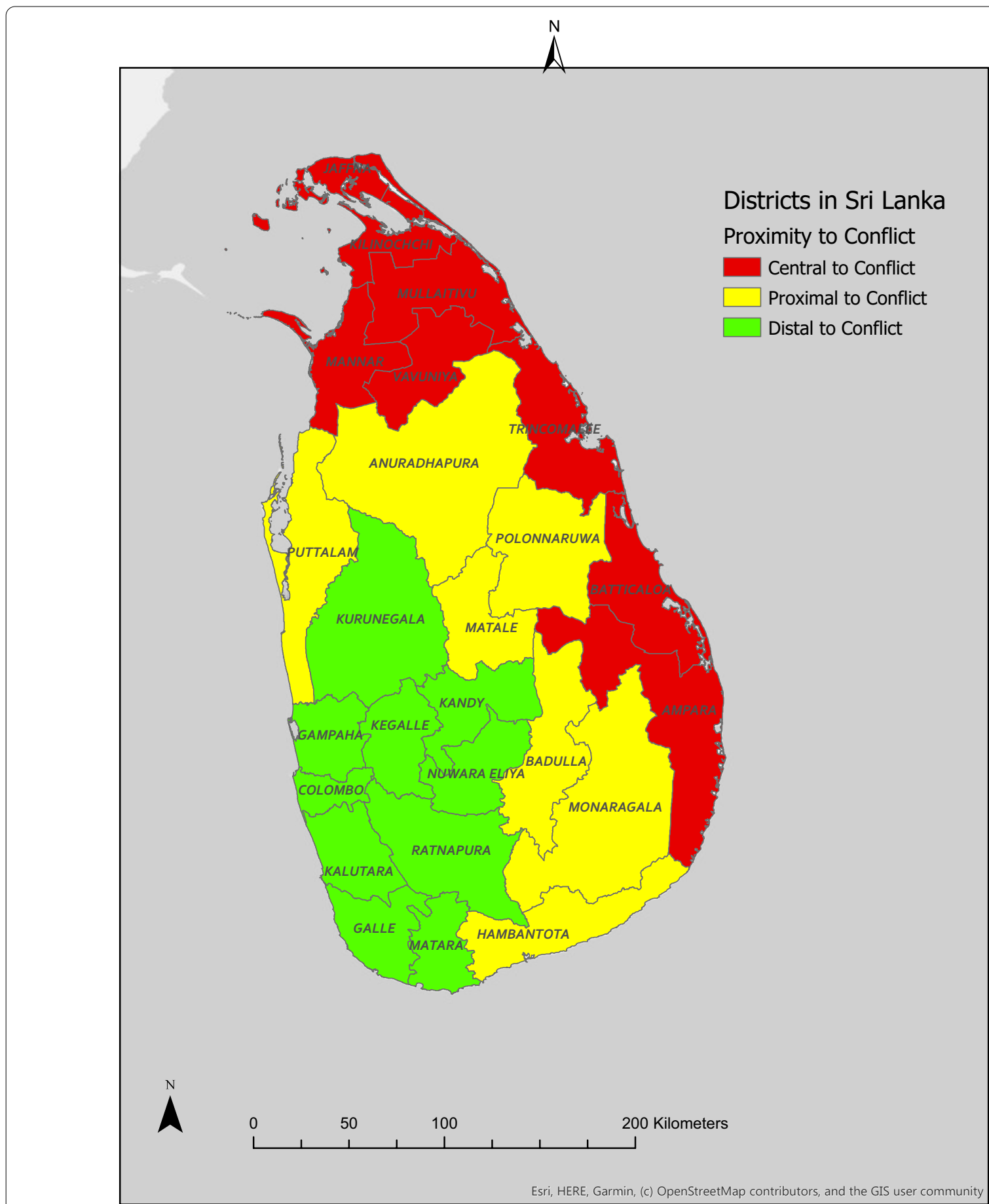

Fig. 1 Map of Sri Lankan Districts. Adapted from Fonseka RW. Understanding gender-based violence and health in post-conflict Sri Lanka. University of California San Diego; 2021

\section{Potential mediator: girl child marriage}

Informed by prior research conducted in Sri Lanka and other countries on conflict, IPV, and girl child marriage, we considered girl child marriage to be a potential mediator of the relationships between proximity to conflict and past year IPV. Girl child marriage was measured as a binary yes/no variable based on whether 
a woman had married or cohabited with a male partner before age 18 .

\section{Covariates}

We included as covariates in the relationship between proximity to conflict and past year IPV variables known or hypothesized to be associated with IPV. These variables included each respondent's age (in years), education (primary or less, secondary, or higher than secondary), household wealth quintile, parity $(0-1,2$, or 3 or more), the age difference between a respondent and her partner (in years), religion (Buddhism, Hinduism, Islam, or other), and ethnicity (Sinhala, Sri Lankan Tamil, or other). Beyond individual-level characteristics, we also included as covariates whether the respondent lived in an urban setting or not, and which district in Sri Lanka she lived in, to control for unmeasured variation at the community level.

\section{Analysis}

We first assessed the distributions of all three forms of past year IPV, proximity to conflict, girl child marriage, and all considered covariates in the sample. Next, we tested if the pairwise distributions of all the variables across past year IPV types were significantly different. We used chi-squared tests for all comparisons across past year IPV type after reducing all variables to categories (ordinal or nominal). In preparation for our multivariable model, we assessed all variables for multicollinearity by calculating their variance inflation factor (VIF); variables with VIF values above 5 were examined for overlap in distribution with other variables in the model. We kept in the analysis all covariates which could be retained with variance inflation factor (VIF) values less than 5, eliminating only ethnicity.

After examining bivariable associations, we conducted a mediation analysis with a series of adjusted logistic regressions, following the four steps suggested by Baron and Kenny [38]. Mediation analysis is a statistical technique that allows researchers to identify possible intermediary pathways between an independent and dependent variable. In our case, based on the literature summarized in the introduction, we considered whether girl child marriage could be the intermediary mechanism linking proximity to conflict to experiencing IPV. The different paths we analyzed are labeled in Fig. 2.

First, we analyzed the relationships between proximity to conflict (the independent variable) and each form of past year IPV (the dependent variables) while excluding girl child marriage (the proposed mediator), modeling the $\mathrm{C}$ path in Fig. 2. Next, we analyzed the relationship between proximity to conflict and girl child marriage, excluding the past year IPV variable being considered

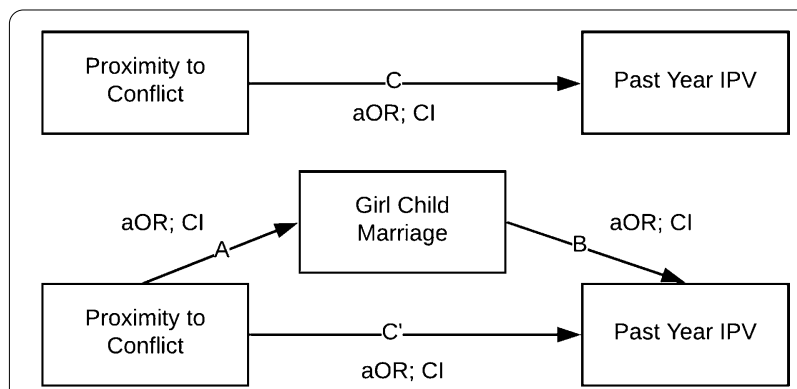

Fig. 2 Measuring whether girl child marriage mediates the relationship between proximity to conflict and past-year intimate partner violence (IPV) in post-conflict Sri Lanka. Legend: aOR: adjusted odds ratio; Cl: 95\% confidence interval

as the dependent variable, modeling the A path in Fig. 2. Finally, we ran full adjusted logistic regression models with proximity to conflict and girl child marriage both included as predictors of each past year IPV variable (calculating the $B$ and $C^{\prime}$ paths in Fig. 2). For a full mediating effect, the adjusted odds ratio (aOR) of proximity to conflict on past year IPV (C) should lose statistical significance ( $C^{\prime}$ p-value greater than 0.05 ) after the mediator is included in the model. A partial mediating effect exists when the impact of proximity to conflict on past year IPV is reduced when girl child marriage is included in the model (the aOR for $C^{\prime}$ is closer to 1 than $C$ ). All statistical analyses were conducted using $\mathrm{R}$ software version 3.6.3 [39], and estimates were weighted using the "survey" package [40] in order to calculate population-representative measures that took into account the complex sampling design of the DHS.

\section{Results}

\section{Descriptive statistics}

Demographic characteristics of the sample and the distribution of past year IPV by characteristic are displayed in Table 1 . The type of past-year IPV most prevalent among respondents was emotional IPV (13\%), while past year sexual IPV had the lowest prevalence (2\%). Over half of the participants lived in districts that were distal to conflict (64\%) and had not been married as children (86\%). Most women had obtained some secondary education (66\%), practiced Buddhism (73\%), and did not live in an urban setting (85\%).

\section{Bivariate analyses between IPV and other variables}

Cross-tabulations of all forms of past year IPV and other variables are presented in Table 1. All forms of past year IPV were most prevalent among women in districts central to conflict and among women who were married as children. Almost all demographic characteristics were 
Table 1 Demographic details of currently partnered women aged 18-49 who participated in the 2016 Sri Lankan DHS Domestic Violence module and distribution of past year sexual, physical, and emotional intimate partner violence (IPV) $(\mathrm{N}=13,691)$

\begin{tabular}{|c|c|c|c|c|c|c|c|c|c|c|c|}
\hline \multirow[b]{2}{*}{ Characteristic } & \multicolumn{2}{|l|}{ Total } & \multicolumn{3}{|c|}{ Past year sexual IPV } & \multicolumn{3}{|c|}{ Past year physical IPV } & \multicolumn{3}{|c|}{ Past year emotional IPV } \\
\hline & n & $\% \wedge$ & n & $\%$ & $\begin{array}{l}\text { Chi-squared } \\
p \text { value }\end{array}$ & $\mathrm{n}$ & $\%$ & $\begin{array}{l}\text { Chi-squared } \\
p \text { value }\end{array}$ & $\mathrm{n}$ & $\%$ & $\begin{array}{l}\text { Chi- } \\
\text { squared } p \\
\text { value }\end{array}$ \\
\hline Total & 13,691 & 100 & 363 & 2 & - & 1290 & 9 & - & 1949 & 13 & - \\
\hline \multicolumn{12}{|l|}{ Proximity to conflict } \\
\hline Distal & 7603 & 64 & 110 & 1 & $<0.01^{*}$ & 529 & $7 \%$ & $<0.01^{*}$ & 867 & 11 & $<0.01^{*}$ \\
\hline Proximal & 3131 & 23 & 60 & 2 & & 247 & 8 & & 261 & 9 & \\
\hline Central & 2957 & 13 & 193 & 8 & & 514 & 19 & & 821 & 29 & \\
\hline \multicolumn{12}{|l|}{ Girl child marriage } \\
\hline No & 11,707 & 86 & 265 & 2 & $<0.01^{*}$ & 967 & 8 & $<0.01^{*}$ & 1539 & 12 & $<0.01^{*}$ \\
\hline Yes & 1984 & 14 & 98 & 5 & & 323 & 16 & & 410 & 19 & \\
\hline \multicolumn{12}{|l|}{$\operatorname{Age}^{\wedge} \wedge$} \\
\hline $18-29$ & 3031 & 22 & 69 & 2 & $0.03^{*}$ & 276 & 8 & $0.04^{*}$ & 394 & 12 & $<0.01^{*}$ \\
\hline $30-39$ & 5852 & 43 & 147 & 2 & & 543 & 8 & & 804 & 13 & \\
\hline $40-49$ & 4808 & 35 & 147 & 3 & & 471 & 10 & & 751 & 15 & \\
\hline \multicolumn{12}{|l|}{ Education } \\
\hline Primary (01-05) or less & 1189 & 8 & 76 & 6 & $<0.01^{*}$ & 234 & 20 & $<0.01^{*}$ & 288 & 24 & $<0.01^{*}$ \\
\hline Secondary (6-12) & 9119 & 66 & 252 & 2 & & 919 & 10 & & 1303 & 13 & \\
\hline Higher than Secondary & 3383 & 26 & 35 & 1 & & 137 & 4 & & 358 & 10 & \\
\hline \multicolumn{12}{|l|}{ Household wealth quintile } \\
\hline Lowest & 3090 & 18 & 169 & 5 & $<0.01^{*}$ & 575 & 19 & $<0.01^{*}$ & 734 & 22 & $<0.01^{*}$ \\
\hline Second & 2787 & 20 & 89 & 3 & & 276 & 10 & & 399 & 14 & \\
\hline Middle & 2683 & 21 & 42 & 2 & & 200 & 7 & & 305 & 11 & \\
\hline Fourth & 2660 & 21 & 33 & 1 & & 146 & 6 & & 270 & 10 & \\
\hline Highest & 2471 & 20 & 30 & 1 & & 93 & 4 & & 241 & 10 & \\
\hline \multicolumn{12}{|l|}{ Parity } \\
\hline $0-1$ & 4267 & 32 & 62 & 1 & $<0.01^{*}$ & 276 & 6 & $<0.01^{*}$ & 475 & 10 & $<0.01^{*}$ \\
\hline 2 & 5154 & 39 & 123 & 2 & & 470 & 9 & & 687 & 12 & \\
\hline $3+$ & 4270 & 29 & 178 & 4 & & 544 & 12 & & 787 & 17 & \\
\hline \multicolumn{12}{|c|}{ Age difference between woman and partner $\wedge \wedge$} \\
\hline Same or older & 2468 & 18 & 77 & 3 & 0.12 & 283 & 11 & $<0.01^{*}$ & 397 & 15 & $0.05^{*}$ \\
\hline $1-5$ years & 6712 & 49 & 176 & 2 & & 628 & 9 & & 911 & 12 & \\
\hline $6-10$ years & 3598 & 27 & 77 & 2 & & 285 & 7 & & 494 & 13 & \\
\hline Over 10 years & 913 & 6 & 33 & 3 & & 94 & 9 & & 147 & 14 & \\
\hline \multicolumn{12}{|l|}{ Religion } \\
\hline Buddhism & 8855 & 73 & 135 & 2 & $<0.01^{*}$ & 585 & 7 & $<0.01^{*}$ & 922 & 11 & $<0.01^{*}$ \\
\hline Hinduism & 2327 & 11 & 127 & 6 & & 417 & 19 & & 624 & 27 & \\
\hline Islam & 1267 & 9 & 59 & 4 & & 132 & 10 & & 195 & 15 & \\
\hline Other & 1242 & 8 & 42 & 3 & & 156 & 12 & & 208 & 15 & \\
\hline \multicolumn{12}{|l|}{ Urban setting } \\
\hline No & 11,510 & 85 & 312 & 2 & 0.85 & 1097 & 9 & 0.56 & 1604 & 13 & $<0.01^{*}$ \\
\hline Yes & 2181 & 15 & 51 & 2 & & 193 & 9 & & 345 & 16 & \\
\hline District $\wedge \wedge \wedge$ & & & & & $<0.01^{*}$ & & & $<0.01^{*}$ & & & $<0.01^{*}$ \\
\hline
\end{tabular}

$\mathrm{n}$ values are unweighted, while percent values are weighted

Chi-squared $\mathrm{p}$-values are weighted according to the survey's complex sampling design

$\wedge$ Total percent values are calculated within the same column, while all other percent values are calculated across the same row

$\wedge \wedge$ Age and age difference between woman and partner are presented in cross-tabulations as categorical but were included in regression models as continuous variables

$\wedge \wedge \wedge$ A full list of districts is omitted due to length (see Additional file 1)

${ }^{*} p<0.05$ 
significantly associated $(p<0.05)$ with each form of IPV. All IPV variables were most prevalent among households with lower wealth, and among women with less education, higher parity, and who practiced Hinduism. Crosstabulations of past year IPV with all districts in Sri Lanka can be found in Additional file 1.

\section{Regression analyses between proximity to conflict and IPV} In our regression models, we controlled for age, education, household wealth quintile, parity, age difference between woman and partner, religion, urban, setting, and district. All regression estimates can be found in Table 2. Not controlling for girl child marriage, women in districts central to conflict were significantly more likely to experience all three forms of past year IPV than women in distal districts, with the greatest increase in odds occurring for past year sexual IPV (aOR 4.19, 95\% Confidence Interval/CI 2.08-8.41). Conversely, women in districts proximal to conflict were significantly less likely to experience past year physical and emotional IPV than women in distal districts, with the greatest reduction in odds occurring for past year emotional IPV (aOR 0.31, CI 0.18-0.54). There was not a significant difference in the odds of sexual IPV between women in districts proximal to conflict and women in distal districts (aOR: 0.34, CI 0.09-1.23).

\section{Mediation analyses of the role of girl child marriage}

All mediation path estimates for past year sexual, physical, and emotional IPV are shown in Fig. 3. The only

Table 2 Logistic regression analyses of the relationship between proximity to conflict, girl child marriage, and past year sexual, physical, and emotional intimate partner violence (IPV) among currently partnered women aged 18-49 who participated in the 2016 Sri Lankan DHS Domestic Violence module $(\mathrm{N}=13,691)$

\begin{tabular}{|c|c|c|c|c|c|c|c|c|c|}
\hline \multirow[b]{2}{*}{ Variable of interest } & \multicolumn{3}{|c|}{ C path (outcome: IPV = yes) } & \multicolumn{3}{|c|}{$\begin{array}{l}\text { A path (outcome: Child } \\
\text { Marriage = yes) }\end{array}$} & \multicolumn{3}{|c|}{$\begin{array}{l}\mathrm{C}^{\prime} \text { and } \mathrm{B} \text { path (outcome: } \\
\mathrm{IPV}=\text { yes) }\end{array}$} \\
\hline & aOR & $\mathrm{Cl}$ & $p$ value & aOR & $\mathrm{Cl}$ & $p$ value & aOR & $\mathrm{Cl}$ & $p$ value \\
\hline \multicolumn{10}{|c|}{ Relationships between proximity to conflict, girl child marriage, and past year sexual IPV (SIPV) } \\
\hline \multicolumn{10}{|l|}{ Proximity to conflict } \\
\hline Distal & ref & ref & ref & ref & ref & ref & ref & ref & ref \\
\hline Proximal & 0.34 & $0.09,1.23$ & 0.10 & 1.28 & $0.83,1.97$ & 0.30 & - & - & - \\
\hline Central & 4.19 & $2.08,8.41$ & $<0.01^{*}$ & 1.89 & $1.22,2.93$ & $<0.01^{*}$ & 4.03 & $2.00,8.12$ & $<0.01^{*}$ \\
\hline \multicolumn{10}{|l|}{ Girl child marriage } \\
\hline No & - & - & - & - & - & - & ref & ref & ref \\
\hline Yes & - & - & - & - & - & - & 1.55 & $1.15,2.09$ & $<0.01^{*}$ \\
\hline \multicolumn{10}{|c|}{ Relationships between proximity to conflict, girl child marriage, and past year physical IPV (PIPV) } \\
\hline \multicolumn{10}{|l|}{ Proximity to conflict } \\
\hline Distal & ref & ref & ref & ref & ref & ref & ref & ref & ref \\
\hline Proximal & 0.51 & $0.29,0.91$ & $0.02^{*}$ & 1.28 & $0.83,1.97$ & 0.30 & - & - & - \\
\hline Central & 2.15 & $1.36,3.41$ & $<0.01^{*}$ & 1.89 & $1.22,2.93$ & $<0.01^{*}$ & 2.07 & $1.30,3.30$ & $<0.01^{*}$ \\
\hline \multicolumn{10}{|l|}{ Girl child marriage } \\
\hline No & - & - & - & - & - & - & ref & ref & ref \\
\hline Yes & - & - & - & - & - & - & 1.62 & $1.37,1.93$ & $<0.01^{*}$ \\
\hline \multicolumn{10}{|c|}{ Relationships between proximity to conflict, girl child marriage, and past year emotional IPV (EIPV) } \\
\hline \multicolumn{10}{|l|}{ Proximity to conflict } \\
\hline Distal & ref & ref & ref & ref & ref & ref & ref & ref & ref \\
\hline Proximal & 0.31 & $0.18,0.54$ & $<0.01^{*}$ & 1.28 & $0.83,1.97$ & 0.30 & - & - & - \\
\hline Central & 1.88 & $1.30,2.70$ & $<0.01^{*}$ & 1.89 & $1.22,2.93$ & $<0.01^{*}$ & 1.82 & $1.26,2.63$ & $<0.01^{*}$ \\
\hline \multicolumn{10}{|l|}{ Girl child marriage } \\
\hline No & - & - & - & - & - & - & ref & ref & ref \\
\hline Yes & - & - & - & - & - & - & 1.45 & $1.23,1.71$ & $<0.01^{*}$ \\
\hline
\end{tabular}

Regression models included as covariates age, education, household wealth quintile, parity, age difference between woman and partner, religion, urban setting, and district

Confidence intervals and p-values are weighted according to the survey's complex sampling design

aOR: adjusted odds ratio; $\mathrm{Cl}: 95 \%$ confidence interval

* $: p<0.05$ 


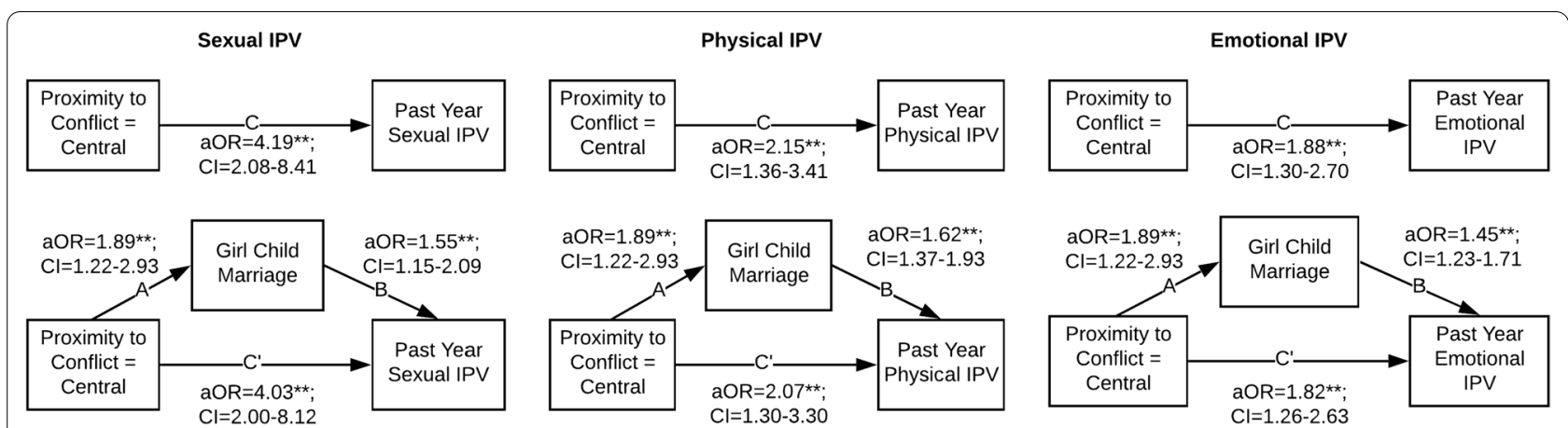

Fig. 3 Measuring whether girl child marriage mediates the relationship between proximity to conflict (comparing central to distal) and past year sexual, physical, and emotional intimate partner violence (IPV) in post-conflict Sri Lanka. Legend: aOR: adjusted odds ratio; Cl: $95 \%$ confidence interval; **: $p<0.01$; odds ratios use proximity to conflict $=$ distal as reference group

significant $(p<0.05)$ association between proximity to conflict and girl child marriage (the A path) was found when comparing districts that were central to conflict to distal districts (aOR 1.89, CI 1.22-2.93, Table 2). Therefore, we only investigated the role of girl child marriage as a mediator of proximity to conflict and IPV (the C' and $\mathrm{B}$ paths) among women in districts central to conflict compared to women in distal districts. We found that the associations between girl child marriage and each form of past year IPV (the B paths) were significant. The adjusted odds ratio of women experiencing each form of past year IPV in districts central to conflict compared to women in distal districts decreased with the addition of girl child marriage (comparing the $\mathrm{C}$ and $\mathrm{C}^{\prime}$ paths) by less than 5 percent (sexual IPV: $4 \%$, physical IPV: $4 \%$, emotional IPV: $3 \%)$, suggesting partial mediation.

\section{Discussion}

Our study provided evidence in support of our hypotheses about the relationships between proximity to conflict, IPV and girl child marriage in post-conflict Sri Lanka. Women in districts central to conflict had increased odds of all forms of past year IPV and girl child marriage compared to women in distal districts. Women who married as children had increased odds of past year sexual, physical, and emotional IPV compared to women who married as adults, and girl child marriage partially mediated the associations between proximity to conflict and past year IPV experience. These findings support and add to the established research on associations between proximity to conflict, IPV and girl child marriage in different settings.

Our study provides evidence from South Asia to add to the growing literature that links centrality to conflict with increased IPV experience in other post-conflict settings, mainly in Sub-Saharan Africa. We found that women in districts central to conflict in Sri Lanka had greater adjusted odds of recent IPV experience than women in distal districts. Qualitative research in post-conflict Uganda has also suggested associations between armed conflict and physical and sexual IPV [41], while quantitative research from post-conflict Liberia found that women living in conflict-affected areas were more likely to experience any past year IPV compared to women in other parts of the country [7]. One framework that might explain the impact on IPV of various explanatory factors, including conflict, is the ecological model adapted by Heise from Bronfenbrenner, which posits that the likelihood of IPV is influenced by many different dimensions of one's environment, from the interpersonal to the societal $[42,43]$. This framework has been further adapted to explicitly consider the role of conflict and post-conflict factors by Swaine et al., who highlighted the role of conflict in normalizing violence and changing gender dynamics in affected communities [44]. These changing post-conflict gender dynamics have been shown in multiple settings to make violence against women and girls more likely $[14,45]$. Our study adds to this literature to further support the idea that women living in conflictaffected areas of a post-conflict country are at increased risk of IPV compared to women living farther from the site of armed conflict.

Our study quantitatively confirms a positive association between centrality to conflict and girl child marriage. Additionally, it provides evidence that girl child marriage partially mediates the positive association between all forms of IPV and centrality to conflict in Sri Lanka. These findings support qualitative research done in Sri Lanka on the links between conflict and girl child marriage as well as similar quantitative studies in other conflict-affected settings of associations between girl child marriage and IPV. A previous study of women and girls' wellbeing in post-conflict Sri Lanka established an elevated prevalence $(31 \%)$ of girl child marriage in conflict 
areas [30]. That same study also collected qualitative data which suggested that the rate of girl child marriage was driven by conflict-related factors such as fear of children's recruitment into militant factions [30]. This conflictrelated strategy of caregivers to "protect" girl children by marrying them has been found in other conflict-affected settings as well, including among Syrian and Sudanese refugee families exposed to conflict [21, 22]. Our findings that suggest girl child marriage partially mediates the increased likelihood of IPV experience among women exposed to conflict are supported by studies from postconflict Uganda and the Democratic Republic of Congo, where girl child marriage was associated with greater likelihood of IPV $[18,46]$. While there are other drivers responsible for a major part of the increased odds of IPV among women living in areas central to conflict, girl child marriage does appear to partially mediate and explain this relationship in Sri Lanka, supporting qualitative claims of its differential practice in conflict and post-conflict areas in Sri Lanka and other research on its association with IPV.

Although our study confirmed that living in areas central to conflict in Sri Lanka is associated with increased IPV and girl child marriage, we found very different relationships in the proximal districts which bordered the conflict zone. Women living in proximal districts had a significantly lower odds of physical and emotional, and marginally significant $(p=0.1)$ lower odds of sexual IPV compared to women in areas distal to conflict. Additionally, there was no significant difference in the odds of girl child marriage in proximal districts compared to distal districts. Other studies on the Sri Lankan conflict suggest some potential explanations for the counterintuitive seeming "protective" effect on IPV among women bordering the conflict areas. One study found increased health utilization in districts bordering the conflict zones, and suggested that people who were able to leave the conflict areas might have done so to access needed health services [47]. This idea of differential mobility, that in wartime some are able to leave and others are not, was reiterated in a 2020 report on collective violence in Sri Lanka [48]. Although the author's focus was on individuals and families able to emigrate from Sri Lanka during wartime, the idea can also be applied to individuals within the country who were able to move outside of the war zone but chose to remain nearby, in the proximal districts. These individuals might have been less at risk for IPV based on structural factors that also allowed them to escape the conflict zones. Men who remained in the conflict areas might be impacted by a larger number of risk factors for post-conflict IPV perpetration such as war-related trauma $[12,13,49]$, alcohol use [10, 11], changing gender norms and roles [14], and conflict- and displacement-related economic stressors including poverty and unemployment $[10,14]$. In contrast, those who were able to move to the proximal areas might have experienced fewer stressors as a result. Additionally, it is possible that these areas closest to the conflict areas have developed greater services and resources than in distal areas based on the need to provide for those fleeing conflict. Researchers in other postconflict settings have highlighted the role that structural factors can play in sustaining IPV beyond the period of armed violence $[7,8]$. It is possible that existing protective factors in the proximal areas where IPV is less likely could be expanded into both conflict-affected and distal areas in order to reduce IPV experience in those areas.

\section{Limitations}

This study had multiple limitations. All responses were collected at the same time, so the relationships we are assessing are only cross-sectional associations, and we cannot infer causality from the findings. Our study is focused on whether child marriage is a mediator of the relationship between proximity to conflict and IPV and we have framed our analyses to address this question. Other researchers with different research questions about the role of variables such as education or parity in the relationship between proximity to conflict and IPV could reproduce our analyses with those variables in the role of mediator. The statistical techniques we used to assess mediation can also be used to identify statistical confounding, and it is possible that the observed relationship in our analyses is one of confounding rather than mediation [50]. Future studies to identify and measure mediation effects could incorporate causal inference techniques in the form of directed acyclic graphs or path diagrams to measure the relationships between the variables of interest. [51].

A small proportion of women reported being married as children, which may have underpowered our analyses to identify significant differences in girl child marriage between women in areas proximal to conflict and those in areas distal to conflict. It is possible that women responding to the survey may have underreported IPV or girl child marriage due to social desirability bias, or that women from districts with differing proximity to conflict recalled IPV experiences differently due to their varied contexts. The DHS questionnaire has been developed and tested in many contexts, including post-conflict settings, and the survey questions have been developed to reduce bias in responses. 52 The survey did not collect complete information on women's location over time, only collecting information on the most recent location that women had moved from. Therefore, we cannot make conclusions about the direct impact of the conflict on survey participants, as it may have varied greatly based on their location over time. For this reason, our "proximity to conflict" 
variable must be interpreted in a post-conflict and crosssectional context, seven years after the end of the Sri Lankan civil war, and as a geographic, rather than experiential, variable. In our partial mediation models, the 95\% confidence intervals for the compared adjusted odds ratios overlap, suggesting that the observed mediation effect could possibly be due to chance. This concern is mitigated by the observation of repeated decreased odds ratios and partial mediation among all types of IPV that were studied.

\section{Conclusions}

In this study, we found that women in areas central to conflict in Sri Lanka had increased odds of experiencing sexual, physical, and emotional IPV compared to women in areas that were distal to conflict. We also found that centrality to conflict was associated with increased odds of girl child marriage, and that girl child marriage partially mediated the association between centrality to conflict and increased odds of IPV. Additionally, we found that women in areas proximal to conflict were less likely to experience IPV and not significantly more likely to experience girl child marriage than women in areas distal to conflict. These findings highlight the long-lasting impact of the Sri Lankan conflict on women and girls' wellbeing and suggest as a possible solution that protective factors and programs that are successfully preventing IPV and girl child marriage in areas bordering the conflict should be expanded into areas central to the conflict to support women and girls living there.

\section{Abbreviations \\ aOR: Adjusted odds ratio; Cl: Confidence interval; DHS: Demographic and health survey; IPV: Intimate partner violence; OR: Odds ratio; SMAM: Singulate mean age of marriage.}

\section{Supplementary Information}

The online version contains supplementary material available at https://doi. org/10.1186/s13031-022-00436-2.

Additional file 1. District of residence of currently partnered women age 18-49 who participated in the 2016 Sri Lanka DHS Domestic Violence module and distribution of past year sexual, physical, and emotional intimate partner violence (IPV) $(\mathrm{N}=13,691)$

\section{Acknowledgements}

The authors would like to thank the Department of Census and Statistics in Sri Lanka for collecting and sharing the data used in this study. Thank you to Dr. Vagisha Gunasekara, Professors M. W. Amarasiri de Silva and Deborah DeGraff, and Emeritus Professor K. A. P. Siddhisena for their assistance in requesting the data. Thank you to Professor Pia Axemo, Professor Kumudu Wijewardena, and Vathsala Illesinghe for providing feedback in the early stages of this project during discussions in Colombo, Sri Lanka. We are grateful to Nabamallika Dehingia for sharing her statistical expertise throughout this study. Thank you to Holly Thurston, PhD, MSW, for her assistance in updating Fig. 1. Thank you as well to Professor Laurie Drabble for her helpful feedback on a revised version of this manuscript. Finally, we would like to express our gratitude to the thousands of women who shared their time and personal information as participants in the 2016 Sri Lankan Demographic and Health Survey.

\section{Authors' contributions}

RWF conceptualized the study, obtained data, performed analyses, and interpreted data for this work. JGS contributed to the study's conceptualization, acquisition of data, and interpretation of the work, and provided significant critical revisions. LM contributed to conceptualization, acquisition of data, and interpretation. $A R, E R$, LU, and RL contributed to the design of the work, interpretation of data, and critical interpretations of the findings. All authors read and approved the submitted manuscript.

\section{Funding}

LM, JGS and AR received funding support for this study from the Bill \& Melinda Gates Foundation as part of the GENDER Project (OPP1179208). The funding body had no role in the design of the study; collection, analysis, and interpretation of data; or in writing the manuscript.

\section{Availability of data and materials}

Data from the 2016 Sri Lankan Demographic and Health Survey can be requested from the Sri Lankan Department of Census and Statistics. Information on requesting this data can be found at the Department's website: http:// www.statistics.gov.lk/.

\section{Declarations}

\section{Ethics approval and consent to participate}

This secondary research was deemed exempt by University of California, San Diego Human Research Protections Program (Project \#191418XX).

\section{Consent for publication}

Not applicable.

\section{Competing interests}

The authors declare that they have no competing interests.

\section{Author details}

${ }^{1}$ Center on Gender Equity and Health (GEH), University of California San Diego School of Medicine, La Jolla, CA, USA. ${ }^{2}$ Joint Doctoral Program in Public Health, San Diego State University and University of California San Diego, San Diego, CA, USA. ${ }^{3}$ Present Address: School of Social Work, San José State University, San Jose, CA, USA. ${ }^{4}$ School of Public Health, San Diego State University, San Diego, CA, USA. ${ }^{5}$ School of Social Work, San Diego State University, San Diego, CA, USA.

Received: 7 May 2021 Accepted: 26 January 2022

Published online: 14 February 2022

\section{References}

1. García-Moreno C, Stöckl H. Violence against women, its prevalence and health consequences. Key Issues Ment Heal. 2013;178:1-11.

2. World Health Organization. Global and regional estimates of violence against women [Internet]. Vol. 53, WHO Press. World Health Organization; 2013 [cited 2018 May 7]. 279-284 p. Available from: www.who.int/about/ licensing/copyright_form/en/index.html

3. Sengupta S. War's End in Sri Lanka: Bloody Family Triumph. The New York Times [Internet]. 2009 May 19; Available from: https://www.nytimes.com/ 2009/05/20/world/asia/20lanka.html

4. de Mel N, Peiris P, Gomez S. Broadening Gender: Why Masculinities Matter: Attitudes, practices and gender-based violence in four districts in Sri Lanka [Internet]. Colombo, Sri Lanka: Care International; 2013. Available from: http://www.care.org/sites/default/files/documents/ Broadening-Gender Why-Masculinities-Matter.pdf

5. Jayatilleke AC, Poudel KC, Yasuoka J, Jayatilleke AU, Jimba M. Intimate partner violence in Sri Lanka. Biosci Trends. 2010;4(3):90-5. 
6. Jayasuriya V, Wijewardena K, Axemo P. Intimate partner violence against women in the capital province of Sri Lanka: Prevalence, risk factors, and help seeking. Violence Against Women. 2011;17(8):1086-102. https://doi.org/10.1177/1077801211417151.

7. Kelly JTD, Colantuoni E, Robinson C, Decker MR. From the battlefield to the bedroom: A multilevel analysis of the links between political conflict and intimate partner violence in Liberia. BMJ Glob Heal. 2018;3(2):e000668.

8. Annan J, Brier M. The risk of return: Intimate partner violence in Northern Uganda's armed conflict. Soc Sci Med. 2010;70(1):152-9.

9. Cherewick M, Kohli A, Remy MM, Murhula CM, Kurhorhwa AKB, Mirindi $A B$, et al. Coping among trauma-affected youth: a qualitative study. Confl Health. 2015;9(1):1-12.

10. Kinyanda E, Weiss HA, Mungherera M, Onyango-Mangen P, Ngabirano E, Kajungu R, et al. Intimate partner violence as seen in post-conflict eastern Uganda: prevalence, risk factors and mental health consequences. BMC Int Health Hum Rights. 2016;16(1):5. https://doi.org/10 1186/s12914-016-0079-x

11. Mootz JJ, Muhanguzi FK, Panko P, Mangen PO, Wainberg ML, Pinsky I, et al. Armed conflict, alcohol misuse, decision-making, and intimate partner violence among women in Northeastern Uganda: a population level study. Confl Health. 2018;12(1):37. https://doi.org/10.1186/ s13031-018-0173-x

12. Østby G. Violence Begets Violence: Armed conflict and domestic sexual violence in Sub-Saharan Africa. HICN Org. 2016;1-35. Available from: www.hicn.org

13. Hossain M, Zimmerman C, Kiss L, Kone D, Bakayoko-Topolska M, Manan DKA, et al. Men's and women's experiences of violence and traumatic events in rural Côte d 'Ivoire before, during and after a period of armed conflict. BMJ Open. 2014;4(2):e003644.

14. Cardoso LF, Gupta J, Shuman S, Cole H, Kpebo D, Falb KL. What factors contribute to intimate partner violence against women in urban, conflict-affected settings? Qualitative findings from Abidjan. Côte d'Ivoire J Urban Heal. 2016;93(2):364-78. https://doi.org/10.1007/ s11524-016-0029-x.

15. Somasundaram D, Sivayokan S. Rebuilding community resilience in a post-war context: developing insight and recommendations - a qualitative study in Northern Sri Lanka. Int J Ment Health Syst. 2013;7(1):3. https://doi.org/10.1186/1752-4458-7-3.

16. Department of Census and Statistics (DCS), Ministry of Health - Nutrition and Indigenous Medicine. Sri Lanka Demographic and Health Survey 2016. Colombo, Sri Lanka; 2017.

17. Bandara P, Knipe D, Munasinghe S, Rajapakse T, Page A. Socioeconomic and geographic correlates of intimate partner violence in Sri Lanka: analysis of the 2016 Demographic and Health Survey. medRxiv [Internet]. 2021;2021.03.21.21254059. https://doi.org/10.1101/2021.03.21. 21254059

18. Landis D, Falb K, Michelis I, Blackomere T, Stark L. Violence, well-being and level of participation in formal education among adolescent girls in eastern Democratic Republic of the Congo: the role of child marriage. Stud Soc Justice. 2018;12(2):273-90.

19. Kidman R. Child marriage and intimate partner violence: a comparative study of 34 countries. Int J Epidemiol. 2017;46(2):662-75. https://doi.org/ 10.1093/ije/dyw225.

20. Hutchinson A, Waterhouse P, March-Mcdonald J, Neal S, Ingham R. Understanding early marriage and transactional sex in the context of armed conflict: Protection at a price. Int Perspect Sex Reprod Health. 2016;42(1):45-9.

21. Gottschalk N. Uganda: early marriage as a form of sexual violence. Forced Migr Rev. 2007;27:3.

22. Mourtada R, Schlecht J, Dejong J. A qualitative study exploring child marriage practices among Syrian conflict-affected populations in Lebanon. Confl Health. 2017;14:11.

23. Raj A. When the mother is a child: The impact of child marriage on the health and human rights of girls [Internet]. Vol. 95, Archives of Disease in Childhood. BMJ Publishing Group Ltd; 2010 [cited 2019 Feb 25]. p. 931-5. Available from: http://www.ncbi.nlm.nih.gov/pubmed/20930011

24. UNICEF. Child marriage - UNICEF DATA [Internet]. [cited 2020 Apr 19]. Available from: https://data.unicef.org/topic/child-protection/child-marri age/
25. Yount KM, Crandall AA, Cheong YF, OsypukTL, Bates LM, Naved RT, et al. Child marriage and intimate partner violence in rural bangladesh: a longitudinal multilevel analysis. Demography. 2016;53(6):1821-52.

26. International Center for Research on Women. Child marriage and domestic violence [Internet]. TOO YOUNG TO WED: Education \& Action Toward Ending Child Marriage. 2006 [cited 2020 Nov 9]. p. 2. Available from: www.icrw.org

27. United Nations Department of Economic and Social Affairs | Population Division. Singulate Mean Age at Marriage [Internet]. [cited 2021 Aug 5]. Available from: https://www.un.org/en/development/desa/population/ publications/dataset/marriage/age-marriage.asp

28. Caldwell BK. Factors affecting female age at marriage in South Asia: Contrasts between Sri Lanka and Bangladesh. Asian Popul Stud. 2005;1(3):283-301.

29. Muslim Marriage and Divorce Act [Internet]. 1975. Available from: https:// www.lawnet.gov.lk/marriage-and-divorce-muslim-4/

30. Kottegoda S, Samuel K, Emmanuel S. Reproductive Health Concerns in Six Conflict-Affected Areas of Sri Lanka. Reprod Health Matters 2008;16(31):75-82.

31. FOKUS WOMEN. Post War Trends in Child Marriage: Sri Lanka [Internet]. 2015. Available from: https://docplayer.net/24861265-Post-war-trends-inchild-marriage-sri-lanka.html

32. Abeywickrama G, Anuranga C. A decomposition analysis of inequalities in Low birth weight in Sri Lanka: findings from the Demographic and Health survey- 2016. Ceylon Med J. 2020;65(1-2):15.

33. Abeywickrama G, Padmadas SS, Hinde A, Padmadas S, Hinde A. Social inequalities in low birthweight outcomes in Sri Lanka: evidence from the Demographic and Health Survey 2016. BMJ Open. 2020;10(5):e037223.

34. Siriwardhana DD, Pathmeswaran A, Wickremasinghe AR. Socioeconomic inequality and determinants of postnatal home visits made by public health midwives: An analysis of the Sri Lanka Demographic and Health Survey. PLoS ONE. 2019;14(4):e0215816. https://doi.org/10.1371/journal. pone.0215816.

35. Chandradasa DGS, Withanage N, Ananda AS. Women's autonomy in household purchasing decision making in Sri Lanka: an application of multivariate baseline-category logit model. Adv Appl Sociol. 2021;11(02):84-98. https://doi.org/10.4236/aasoci.2021.112007.

36. Ellsberg M, Heise L. Researching Violence Against Women. A Practical Guide for Researchers and Activists [Internet]. Washington, DC, United States: PATH; 2005. Available from: https://www.who.int/reproductivehea Ith/publications/violence/9241546476/en/

37. Loaiza Sr. E, Wong S. Marrying Too Young: End Child Marriage [Internet]. Vol. 11, United Nations Population Fund UNFPA. UNFPA; 2012 [cited 2021 Jan 31]. Available from: https://www.unfpa.org/sites/default/files/pubpdf/MarryingTooYoung.pdf

38. Baron RM, Kenny DA. The moderator-mediator variable distinction in social psychological research. Conceptual, strategic, and statistical considerations. J Pers Soc Psychol. 1986;51(6):1173-82.

39. Chambers J. Software for data analysis: programming with R. Springer; 2008.

40. Lumley T. Package "survey": Analysis of complex survey samples. [Internet]. Version 3.30-3. 2015. Available from: https://cran.r-project.org/web/ packages/survey/survey.pdf

41. Mootz JJ, Stabb SD, Mollen D. Gender-based violence and armed conflict: a community-informed socioecological conceptual model from Northeastern Uganda. Psychol Women Q. 2017;41(3):368-88. https://doi.org/ $10.1177 / 0361684317705086$.

42. Heise LL. Violence against women: an integrated, ecological framework. Violence Against Women. 1998;4(3):262-90. https://doi.org/10.1177/ 1077801298004003002.

43. Bronfenbrenner U. Ecological systems theory. In: Six theories of child development: Revised formulations and current issues. London, England: Jessica Kingsley Publishers; 1992. p. 187-249.

44. Swaine A, Spearing M, Murphy M, Contreras-Urbina M. Exploring the intersection of violence against women and girls with post-conflict statebuilding and peacebuilding processes: a new analytical framework. J Peacebuilding Dev. 2019;14(1):3-21.

45. Stark L, Asghar K, Yu G, Bora C, Baysa AA, Falb KL. Prevalence and associated risk factors of violence against conflict-affected female adolescents: a multi-country, cross-sectional study. J Glob Health. 2017;7(1). 
46. Odimegwu C, Frade S. The influence of adolescent age at first union on physical intimate partner violence and fertility in Uganda: A path analysis. SAJCH South African J Child Heal. 2018;12(Special Issue):S51-6.

47. Johnson SA. The Cost of War on Public Health: An exploratory method for understanding the impact of conflict on public health in Sri Lanka. PLoS ONE. 2017;12(1):166674. https://doi.org/10.1371/journal.pone.0166674.

48. Silva KT. What caused the repeated outbreak of violent social eruptions in Sri Lanka during past five decades and what can be done to prevent such upheavals in future? Report on reflections by civil society actors. 2020.

49. Fonseka RW, Minnis AM, Gomez AM. Impact of adverse childhood experiences on intimate partner violence perpetration among Sri Lankan men. PLOS ONE. 2015;10(8):e0136321.

50. MacKinnon DP, Fairchild AJ, Fritz MS. Mediation analysis. Annu Rev Psychol. 2007;58(1):593-614. https://doi.org/10.1146/annurev.psych.58. 110405.085542.

51. Hernán MA, Robins JM. Instruments for causal inference: An epidemiologist's dream? Epidemiology [Internet]. 2006 Jul [cited 2021 Aug 13];17(4):360-72. Available from: https://journals.Iww.com/epidem/Fullt ext/2006/07000/Instruments_for_Causal_Inference_An.4.aspx

52. DHS. Demographic Health Survey Questionnaires and Modules: Domestic Violence Module [Internet]. 2020. Available from: https://dhsprogram. com/publications/publication-DHSQMP-DHS-Questionnaires-and-Manua Is.cfm

\section{Publisher's Note}

Springer Nature remains neutral with regard to jurisdictional claims in published maps and institutional affiliations.

- fast, convenient online submission

- thorough peer review by experienced researchers in your field

- rapid publication on acceptance

- support for research data, including large and complex data types

- gold Open Access which fosters wider collaboration and increased citations

- maximum visibility for your research: over $100 \mathrm{M}$ website views per year

At BMC, research is always in progress.

Learn more biomedcentral.com/submissions 